\title{
A INTERPRETAÇÃO DO DIREITO PRIVADO NO SUPERIOR TRIBUNAL DE JUSTIÇA E A UTILIZAÇÃO DO DISCURSO "CONSTITUCIONALIZANTE”
}

\author{
Andrea Sales Santiago Schmidti \\ Janile Lima Viana \\ Leonardo José Peixoto Lealiii
}

\section{RESUMO}

Mediante o desenvolvimento de pesquisa empírica na base de jurisprudência disponível no sitio eletrônico do Superior Tribunal de Justiça (STJ), delimitada no período de 07/04/1989 a 01/12/2017, com o emprego dos metadados "constitucionalização"; "civil-constitucional"; "despatrimonialização"; "repersonalização direito civil"; "publicização direito civil" e "eficácia dos direitos fundamentais", este último com e sem aspas, buscou-se investigar a utilização do discurso constitucionalizante na jurisprudência daquele Tribunal e se constatou, alicerçados nos resultados encontrados, que os fundamentos constitucionais são frequentemente utilizados para a solução das lides, a despeito da legislação ordinária existente. A metodologia empregada neste estudo foi empírica e hipotético-dedutiva. A discussão, portanto, sobre a Teoria do Direito CivilConstitucional passa a ser de fundamental importância para a correta compreensão e aplicação das categorias e conceitos do Direito Civil ante as situações práticas apresentadas.

PALAVRAS-CHAVE: Direito Civil; constitucionalização; civil-constitucional; metadados; eficácia dos direitos fundamentais..

' Pesquisadora independente; "Universidade Católica de Pernambuco, Faculdade de Direito, Fortaleza/CE, ORCID; iii Universidade de Fortaleza, Faculdade de Direito, Fortaleza/CE. 


\title{
THE INTERPRETATION OF PRIVATE LAW IN THE SUPERIOR COURT OF JUSTICE AND THE USE OF THE "CONSTITUTIONALIZING" SPEECH
}

\author{
Andrea Sales Santiago Schmidt \\ Janile Lima Viana \\ Leonardo José Peixoto Leal
}

\begin{abstract}
Through the development of an empirical research based on the jurisprudence available in the electronic site of the Superior Court of Justice (STJ), delimited in the period between 07/04/1989 and 12/01/2017, using the metadata "constitutionalisation"; "constitutional civil"; "depatrimonialization"; "civil law repersonalization"; "civil rights disclosure" and "effectiveness of fundamental rights", this one with or without quotes, it was sought to investigate the use of the constitutionalising discourse in the jurisprudence of that Superior Court and it was found, based on the results found, that the constitutional foundations are frequently used for the resolution of the lawsuits, in spite of the existing ordinary legislation. The methodology used in this study was empirical and hypotheticaldeductive. The discussion, therefore, on the Theory of Civil Law-Constitutional becomes of fundamental importance for the correct understanding and application of the categories and concepts of Civil Law before the practical situations presented.
\end{abstract}

KEYWORDS: Civil Right; constitutionalisation; civil-constitutional; metadata; effectiveness of fundamental rights. 


\section{INTRODUÇÃO}

Após a promulgação da Constituição da República Federativa do Brasil de 1988, começou-se a falar em constitucionalização do Direito Civil, que embora represente um conceito plurissignificativo, pouco suscetível ao consenso semântico, é hoje um discurso quase hegemônico na doutrina civilista brasileira.

Anos após, surgiu também o movimento do Direito Civil-Constitucional, que passou a atacar o Direito Civil em sua formulação clássica, elaborando um discurso constitucionalizante em matérias de Direito Privado.

Por tal pretexto, o presente trabalho busca responder à seguinte pergunta inaugural: em que medida o discurso constitucionalizante adotado pela doutrina influencia o posicionamento do Superior Tribunal de Justiça?

Dessa indagação de ordem geral originam-se estes questionamentos específicos: (i) o discurso constitucionalizante é usado na jurisprudência recorrente em Direito Privado do Superior Tribunal de Justiça? (ii) Nos casos encontrados, há necessidade argumentativa do uso desse discurso para o deslinde dos casos?

Assim, busca-se com este ensaio, realizar uma abordagem sobre o discurso constitucionalizante adotado pelo Superior Tribunal de Justiça, mediante a análise de metadados utilizados pela doutrina para explicar o fenômeno da constitucionalização do Direito Civil, ressaltando um quadro geral dos acórdãos. Bem assim, pretende-se proceder ao exame das decisões sobre alguns acórdãos que utilizaram essa argumentação para a resolução dos casos, modificando sensivelmente a matéria sob observação.

A metodologia aplicada nesta pesquisa é do tipo empírica, com emprego de expressões determinadas, chamadas de metadados, na base de jurisprudência do Superior Tribunal de Justiça. O método a que se recorreu é o hipotéticodedutivo, em razão da busca se iniciar com base em hipóteses que, ao final, serão ratificadas ou contraditas.

Da mesma maneira, após o resultado geral de acórdãos, serão aplicadas as técnicas de depuração e de refinamento, para se restringir a análise do discurso constitucionalizante somente aos relativos a Direito Civil.

\section{DISCURSO CONSTITUCIONALIZANTE}


$\mathrm{Na}$ doutrina civilista contemporânea, com frequência, ocorre a ideia de "constitucionalização", o que também acontece na jurisprudência brasileira. E o primeiro problema expresso é a plurissignificação do termo. Afinal, o que significa constitucionalização? Não há um acordo semântico que elucide a questão entre os próprios doutrinadores que se valem dessa ideia.

Silva (2014, p. 38) aduz que "quando se fala em constitucionalização do direito, a ideia mestra é a irradiação dos efeitos das normas (ou valores) constitucionais aos outros ramos do direito". Para esse autor, portanto, é a constitucionalização a via de irradiação das normas constitucionais pelo ordenamento jurídico.

Lôbo (1999), reporta-se à constitucionalização definindo-a "como o processo de elevação ao plano constitucional dos princípios fundamentais do direito civil, que passam a condicionar a observância pelos cidadãos, e aplicação pelos tribunais, da legislação infraconstitucional". Esse autor faz a diferença entre "publicização" e "constitucionalização", ao estabelecer que esta tem "por filtro submeter o direito positivo aos fundamentos de validade constitucionalmente estabelecidos", enquanto aquela deve ser entendida "como o processo de intervenção legislativa infraconstitucional." (p. 100)

Moraes (2006) estabelece que os institutos clássicos do Direito Civil devem ser operacionalizados em consonância com as finalidades da Constituição Federal, cujo objetivo é "dar maior eficácia ao texto, com suporte na elevação da pessoa humana ao centro do ordenamento jurídico, o que possibilitou uma transformação da ordem jurídica privada". (pp. 234-235)

Barroso (2005) considera dois aspectos que influenciaram na constitucionalização do Direito Civil, a uma, a irradiação da dignidade da pessoa humana, promovendo uma "despatrimonialização" ou "repersonalização" do Direito Civil; a duas, a aplicação dos direitos fundamentais nas relações privadas, compreendendo a constitucionalização "como um filtro axiológico pelo qual se deve ler o direito civil." (pp. 32-34)

Fachin (2008) defende a ideia da "dimensão prospectiva do texto constitucional, relevante para ser polo irradiador de eficácia das relações jurídicas de titularidade, do trânsito jurídico e do projeto parental." (p. 7)

Em 1991, três anos após promulgada a Constituição Federal no Brasil, traduziu-se a obra do italiano Pietro Perlingieri, intitulada como "Perfis do Direito Civil" e com o subtítulo "Introdução ao Direito Civil Constitucional", inicialmente 
publicada na Revista Brasileira de Direito Civil. Desde então surgiu outro movimento do Direito Civil, o chamado "civil-constitucional", que passou a combater, indiscriminadamente, o Direito Civil na sua formulação clássica.

Para Moraes (2010) o Direito Civil-Constitucional "pressupõe a incidência direta, e imediata, das regras e princípios constitucionais sobre todas as relações interprivadas." (p. 29)

Schreiber (2013) acentua, a seu turno, que, para o movimento do Direito Civil-Constitucional, "o que importa é obter a máxima realização dos valores constitucionais no campo das relações privadas, não interessando se a Constituição é aplicada de forma direta ou indireta." (p. 6)

De fato, o que seria tão somente o pensamento de um autor italiano sem grandes repercussões em seu próprio país de origem, chegou ao Brasil como escola dominante de Direito Civil, com poucos focos de resistência.

Em entrevista ao professor Rodrigues (2014), Nery Jr. faz uma crítica às escolas ou correntes específicas de Direito Civil-Constitucional, arguindo que "nosso direito já possui mecanismos suficientemente importantes e fortes para dispensar esse tipo de approach de direito civil-constitucional, de direito alternativo ou diálogo das fontes." (p. 375)

Dentre os autores que resistem ao emprego indiscriminado dos princípios constitucionais ante a existência de legislação infraconstitucional disciplinando a matéria, pode-se citar Streck (2012, p. 9, grifo do autor), pois critica veementemente tal prática, destacando a ideia de pamprincipiologia como:

Uma espécie de patologia especialmente ligada às práticas jurídicas brasileiras e que leva ao uso desmedido de standards argumentativos que, no mais das vezes, são articulados para driblar aquilo que ficou regrado pela produção democrática do direito, no âmbito da legislação (constitucionalmente adequada).

No mesmo sentido, Reis (2017) destaca a indiferença dos julgadores com os aspectos metodológicos e da essência das concepções do Direito Privado, afirmando que "A euforia com que princípios, funções e modelos interpretativos são celebrados pela doutrina e praticados pela jurisprudência parece ser inversamente proporcional à disposição da nossa cultura jurídica em analisá-los e discuti-los criticamente." (p. 214) 
Azevedo, em entrevista concedida a Tepedino (2008), defende o emprego da Constituição Federal de forma direta nas relações privadas, porém desde que " em caso de lacuna da legislação ordinária ou quando a lei ordinária se contrariar a ela, pois será expulsa do sistema e a constituição é aplicada em seu lugar." (p. 307)

Mostra-se na doutrina - e será investigado se o mesmo ocorre na jurisprudência do Superior Tribunal de Justiça - que a expressão "constitucionalização do Direito Civil" não denota sequer um acordo semântico e que representa, na maioria das vezes, o uso indiscriminado da Constituição nas relações privadas, a despeito da existência de norma infraconstitucional válida.

\section{PESQUISA JURISPRUDENCIAL}

Foram efetuadas pesquisas na Base de Jurisprudência do Superior Tribunal de Justiça, com o objetivo de investigar a utilização do discurso constitucionalizante naquela Corte e a necessidade argumentativa desse emprego nos casos encontrados.

\subsection{METADADOS UTILIZADOS NA PESQUISA}

A pesquisa dos julgados foi realizada no sítio eletrônico do Superior Tribunal de Justiça, por ser essa a Corte responsável pela uniformização do Direito ordinário no Brasil. Além disso, é o único tribunal superior em que se tem a absoluta certeza de que todos os acórdãos são publicados e disponibilizados na base de consulta jurisprudencial desde a sua fundação. Em 2004, inclusive, passou a ser possível a consulta na internet do inteiro teor dos acórdãos, antes mesmo de serem publicados no Diário da Justiça (Superior Tribunal de Justiça, 2004, p. 1).

Delimitou-se o espaço temporal da pesquisa no intervalo compreendido entre 07/04/1989, por ser esse o dia, mês e ano de sua instalação e 01/12/2017.

A jurisprudência do STJ disponibiliza a consulta a diversas bases de dados. Ao acessar o link Pesquisa, as bases "Acórdãos", "Súmulas", "Decisões Monocráticas" e "Informativos de Jurisprudência" aparecem automaticamente selecionadas. Para esta curta investigação, contudo, recorreu-se somente à base 
dos acórdãos, pois o que se busca é o entendimento do Tribunal, que somente será alcançado em decisões colegiadas.

A pesquisa foi feita no campo livre, com o operador padrão "E", de modo que o sistema buscou documentos que obrigatoriamente contivessem as palavras digitadas, pouco importando a ordem ou a distância em que se encontrassem.

Com amparo no discurso constitucionalizante na doutrina brasileira, verificaram-se as expressões que mais se repetiram nos conceitos, as quais foram utilizadas como metadados para a pesquisa jurisprudencial:
A) "Constitucionalização"
B) "Civil-Constitucional"
C) "Despatrimonialização"
D) "Repersonalização do direito civil"
E) "Eficácia dos direitos fundamentais"
F) Eficácia dos direitos fundamentais (sem aspas)

Para fins de resultado, observou-se que é indiferente a digitação de palavras com letras maiúsculas, minúsculas ou acentuadas. O sistema do Superior Tribunal de Justiça também não distingue o "c" do "ç".

A pesquisa foi feita, enquadrando-se os metadados com e sem as aspas, a fim de se obter informações mais completas, pois o operador "", no campo de pesquisa livre na base da jurisprudência do Superior Tribunal de Justiça, é usado para localizar expressões exatas.

Após o levantamento geral dos metadados, aplicou-se a técnica de refinamento para excluir os acórdãos que não fossem de Direito Civil e aqueles em que não houve julgamento de mérito, bem como os acórdãos que não guardavam relação com o tema proposto. Sob apoio dos resultados encontrados, procedeu-se ao exame manual de cada julgado (realizado pelos autores deste artigo) para a verificação do seu conteúdo, de modo a averiguar a necessidade argumentativa do uso do discurso constitucionalizante.

\subsection{DADOS ENCONTRADOS PARA ANÁLISE}


Neste tópico será abordada a pesquisa ampla dos metadados para se aplicar a técnica de refinamento e apurar os acórdãos para posterior estudo.

\section{A) METADADO "CONSTITUCIONALIZAÇÃO"}

A primeira análise foi realizada com o metadado "constitucionalização", visto ser o fenômeno que a doutrina vem apontando como modificador do Direito Civil. Foram encontrados 15 acórdãos, dos quais sete de Direito Administrativo, um de Processo Civil, 2 de Direito Civil (Família e Alienação Fiduciária) e cinco acórdãos de Direito Tributário, como mostra a Figura 1, a seguir:

\section{Figura 1.}

Processos que abordam o termo "constitucionalização".

- Direito Administrativo 07

- Processo Civil 01

Direito Civil 02

Direito Tributário 05
Processos que abordam o termo "constitucionalização"

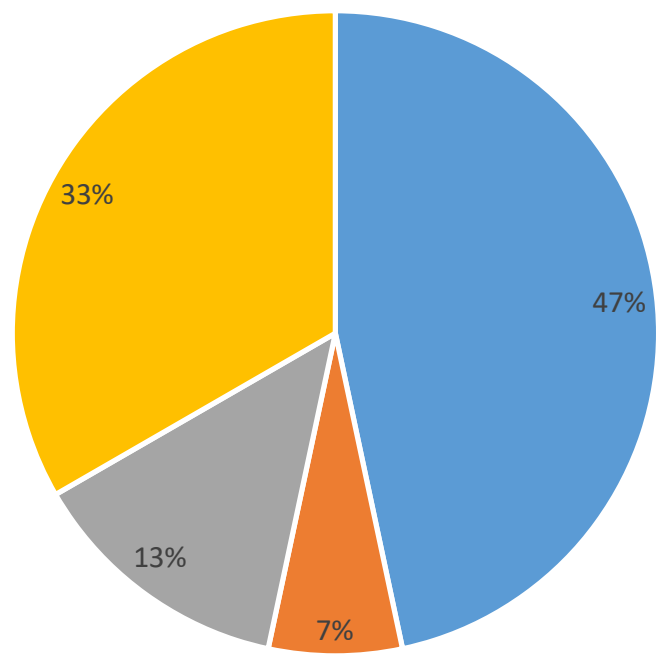

Aplicando-se a técnica de refinamento, somente 2 acórdãos interessam à pesquisa, que são de Direito Civil: o REsp 1183378, na matéria de Direito de Família, que versou sobre o casamento entre pessoas do mesmo sexo; e o HC 12547, que tratou sobre a prisão civil por dívida em contrato de alienação fiduciária (Tabela 1).

\section{Tabela 1}

Processos que Abordam o Termo "Constitucionalização" na Área do Direito Civil

Processo Matéria Assunto Julgamento Estado




\begin{tabular}{lllll}
\hline REsp & Família & $\begin{array}{l}\text { Casamento Civil } \\
\text { (homoafetivo) }\end{array}$ & 25/10/2011 & $\begin{array}{l}\text { Rio Grande do } \\
\text { Sul }\end{array}$ \\
HC 12547 & $\begin{array}{l}\text { Alienação } \\
\text { Fiduciária }\end{array}$ & Prisão Civil & 01/06/2000 & Distrito Federal \\
\hline
\end{tabular}

B) METADADO “CIVIL-CONSTITUCIONAL"

A utilização do metadado civil-constitucional culminou no aparecimento de 11 resultados, dos quais dois de Direito Administrativo, dois de Processo Civil e sete de Direito Civil, cuja distribuição pode ser visualizada na Figura 2, na sequência:

\section{Figura 2}

Processos que abordam o termo "civil-constitucional"

Processos que abordam o termo "civil-constitucional"

- Direito Administrativo 02

- Processo Civil 02

Direito Civil 07

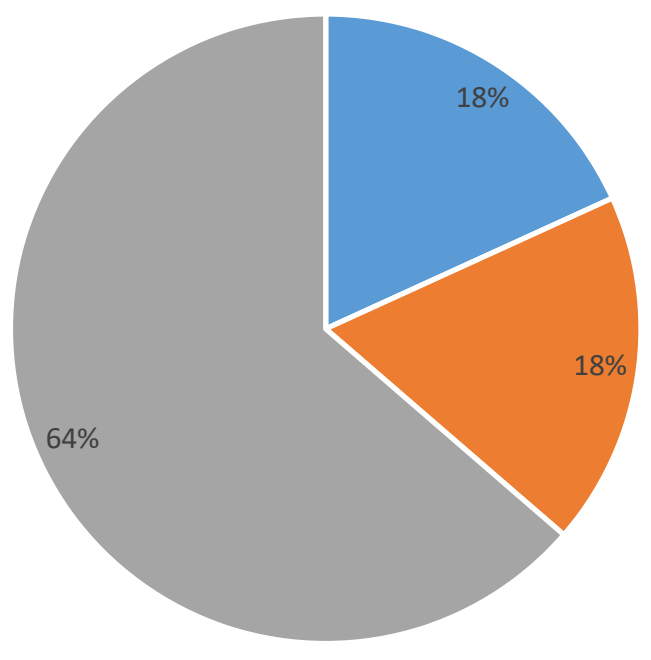

Aplicando-se a técnica de refinamento, verificou-se que, do resultado encontrado, sete acórdãos são de Direito Civil: REsp 1365279; REsp 1299866; REsp 1258389; REsp 1292620; REsp 1335153; REsp 1334097; e REsp 669904 (Tabela 2).

\section{Tabela 2}


Processos que Abordam o Termo "Civil-Constitucional" na Área do Direito Civil

\begin{tabular}{|c|c|c|c|c|}
\hline Processo & Matéria & Assunto & Julgamento & Estado \\
\hline REsp 1365279 & Condomínio & Multa & $25 / 08 / 2015$ & São Paulo \\
\hline $\begin{array}{l}\text { REsp } \\
1299866\end{array}$ & Família & Outorga uxória & $25 / 04 / 214$ & DF \\
\hline $\begin{array}{l}\text { REsp } \\
1258389\end{array}$ & $\begin{array}{l}\text { Responsabilidad } \\
\text { e Civil }\end{array}$ & Dano moral & $17 / 12 / 2013$ & Paraíba \\
\hline $\begin{array}{l}\text { REsp } \\
1292620\end{array}$ & $\begin{array}{l}\text { Direito } \\
\text { intertemporal }\end{array}$ & Escritura Pública & $25 / 06 / 2013$ & Rio de Janeiro \\
\hline $\begin{array}{l}\text { REsp } 1335153 \\
\text { REsp } \\
1334097\end{array}$ & $\begin{array}{l}\text { Direito de } \\
\text { Personalidade }\end{array}$ & $\begin{array}{l}\text { Direito ao } \\
\text { esquecimento }\end{array}$ & 28/05/2013 & Rio de Janeiro \\
\hline REsp 669904 & Seguro & $\begin{array}{l}\text { Inadimplência } \\
\text { do pagamento } \\
\text { do prêmio }\end{array}$ & 04/03/2008 & $\begin{array}{l}\text { Rio Grande do } \\
\text { Sul }\end{array}$ \\
\hline
\end{tabular}

C) METADADOS "REPERSONALIZAÇÃO" E "PUBLICIZAÇÃO DO DIREITO CIVIL"

Não foram encontrados acórdãos com as referidas expressões.

D) METADADO “DESPATRIMONIALIZAÇÃO”

Obtiveram-se da referida pesquisa dois acórdãos referentes à disciplina de Processo Civil, cujo conteúdo não possui relação com os conceitos expostos.

E) METADADO "EFICÁCIA DOS DIREITOS FUNDAMENTAIS"

O emprego do metadado "eficácia dos direitos fundamentais" resultou em 12 acórdãos, dois de Direito do Consumidor, um de Processo Civil, um de Direito Aeronáutico e oito de Direito Civil, como disposto na Figura 3, a seguir:

\section{Figura 3}

Processos que abordam o termo "eficácia dos direitos fundamentais". 
Processos que abordam o termo "eficácia dos direitos fundamentais"

Consumidor 02

- Processo Civil 01

- Direito Aeronáutico 01

Direito Civil 08

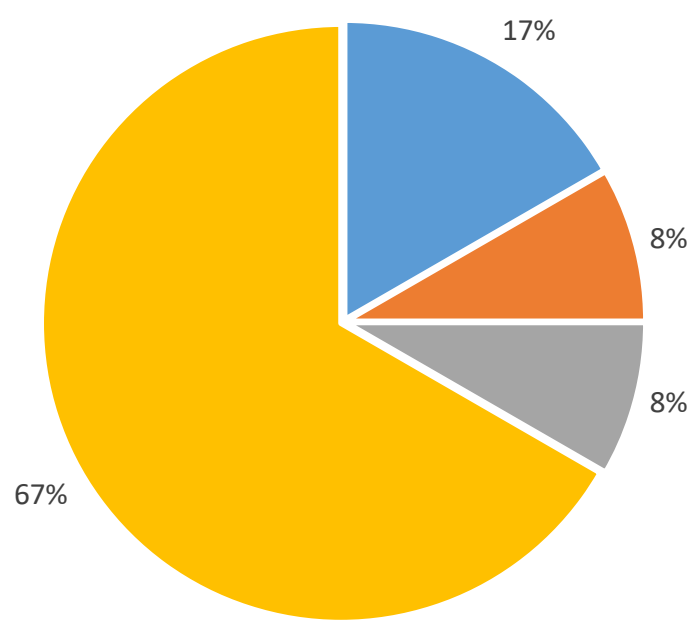

Em relação a esse metadado, os resultados foram diversos com e sem o uso do operador aspas. Aplicando-se a técnica de refinamento no metadado com a utilização das aspas, restaram 2 acórdãos de Direito Civil, o REsp 1179259, que tem como matéria o usufruto, em que o STJ fez uma análise do artigo 1.410, VIII, com origem no princípio da função social da propriedade; e o HC 12547, que também figurou no resultado do metadado "constitucionalização" (Tabela 3).

\section{Tabela 3}

Processos que Abordam o Termo "Eficácia dos Direitos Fundamentais" na Área do Direito Civil

\begin{tabular}{lllll}
\hline Processo & Matéria & Assunto & Julgamento & Estado \\
\hline REsp 1179259 & Usufruto & Prazo & $14 / 05 / 2103$ & Minas Gerais \\
HC 12547 & Alienação & Prisão Civil & $01 / 06 / 2000$ & Distrito Federal \\
& Fiduciária & & & \\
\hline
\end{tabular}

F) METADADO EFICÁCIA DOS DIREITOS FUNDAMENTAIS SEM ASPAS

Como resultado de análise geral, encontraram-se 58 acórdãos, sendo 11 de Processo Civil, oito de Processo Penal, 14 de Direito Administrativo, um de Direito Penal, um de Direito Ambiental, quatro de Direito do Consumidor, dois de Direito 
Previdenciário, três de Direito Tributário, um de Direito Aeronáutico (já em outro metadado), dois de Estatuto da Criança e do Adolescente e 11 de Direito Civil. Vejase a Figura 4 a seguir:

\section{Figura 4}

Processos que abordam o termo eficácia dos direitos fundamentais sem aspas

Processos que abordam o termo eficácia dos direitos fundamentais sem aspas

Processo Civil 11

Processo Penal 08

Direito Administrativo 14

Direito Penal 01

- Direito Ambiental 01

Direito do Consumidor 04

- Direito Previdenciário 02

- Direito Tributário 03

- Direito Aeronáutico 01

Estatuto da Criança e Adolescente 02

- Direito Civil 11

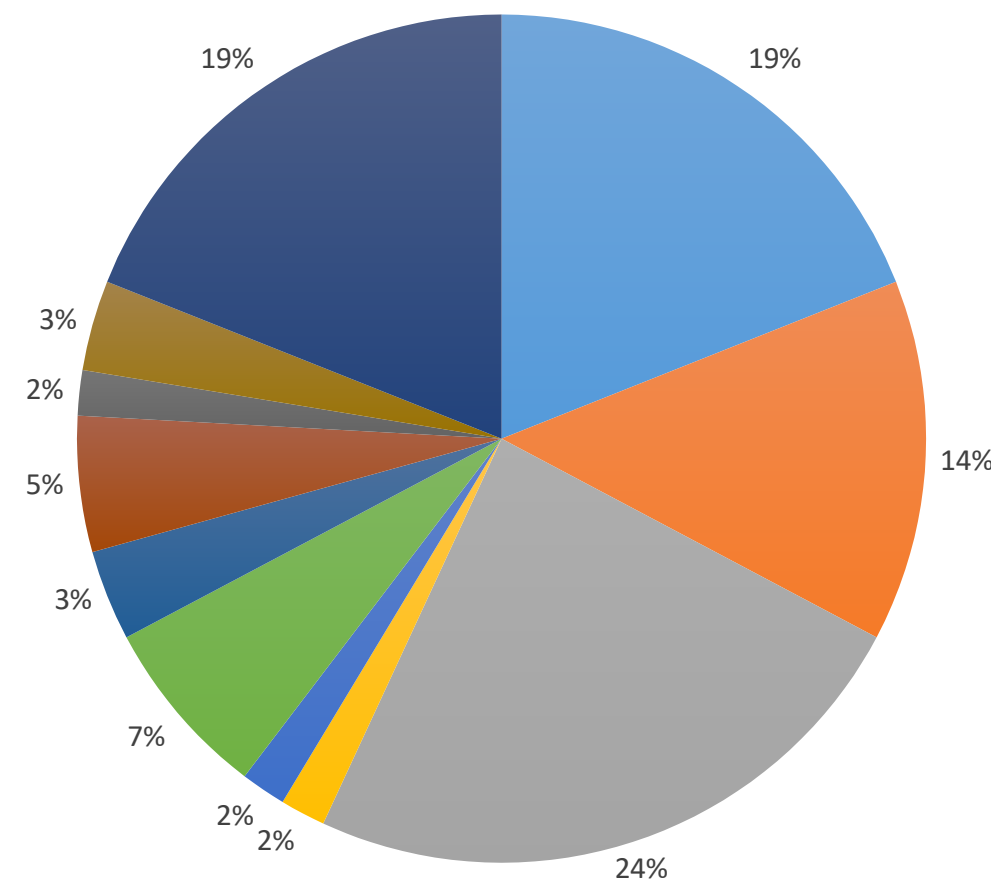

Já com relação à disciplina Direito Civil, cerne do trabalho, a pesquisa com base no metadado resultou em 11 acórdãos. Ao utilizar, contudo, a técnica de refinamento, excluídos os acórdãos repetidos em outro metadado e os que não possuem alteração na sua essência sobre o discurso constitucionalizante, restaram dois acórdãos, quais sejam: o REsp 1626739, que cuida de Ação de retificação de registro, e o Aglnt no AREsp 330494, sobre o direito de associação, que serão analisados posteriormente (Tabela 4).

\section{Tabela 4}

Processos que Abordam o Termo Eficácia dos Direitos Fundamentais sem Aspas na Área do Direito Civil

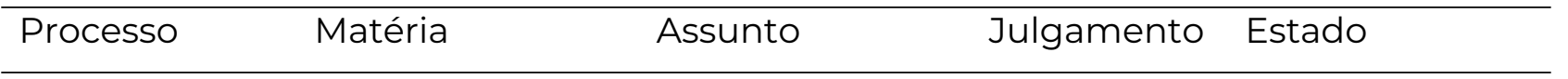




\begin{tabular}{|c|c|c|c|c|c|}
\hline & Ação & de & Cirurgia & & \\
\hline REsp 1626739 & $\begin{array}{l}\text { retificação } \\
\text { registro }\end{array}$ & de & $\begin{array}{l}\text { transgenitalizaç } \\
\text { ão }\end{array}$ & 09/05/2017 & $\begin{array}{l}\text { Rio Grande do } \\
\text { Sul }\end{array}$ \\
\hline
\end{tabular}

Aglnt no Associação civil AREsp 330494

\section{Direito}

de associação 29/09/2016 São Paulo

Impõe-se evidenciar o fato de que, no levantamento geral por disciplinas, diversos acórdãos não apresentaram vinculação com a eficácia de direitos fundamentais, revelando apenas expressões como "eficácia" ou "fundamentais", sem relação com os conceitos ora expostos.

\subsection{ACÓRDÃOS GERAIS DE DIREITO CIVIL POR METADADOS}

Dentre os metadados utilizados na pesquisa (Figura 5), destacaram-se dois, que exprimiram resultados maiores: "civil-constitucional" e eficácia dos direitos fundamentais (sem a utilização das aspas).

Na divisão por ano (Figura 6), logo a seguir, percebem-se picos nos anos de 2000 e 2013, mas ainda de maneira inexpressiva. Já na divisão por Estado (Figura 7), é possível localizar em São Paulo a origem do maior índice de processos sobre o tema, o que se torna compreensível, por ser a capital do estado de igual nome ao município mais populoso do Brasil.

\section{Figura 5}

Acórdãos de Direito Civil encontrados por metadados. 
Acórdãos de Direito Civil encontrados por metadados

- Constitucionalização 02

- Eficácia dos direitos fundamentais 06

a Civil-Constitucional 07

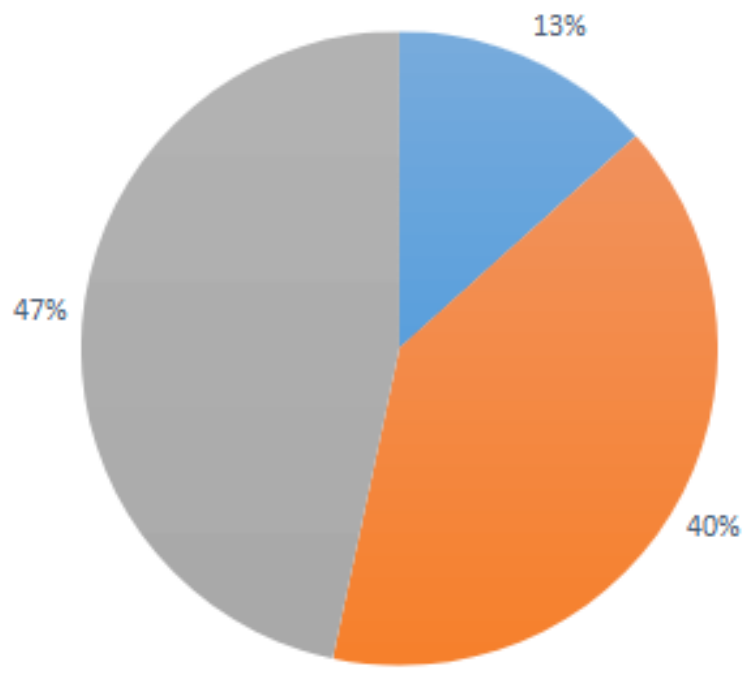

A) DIVISÃO POR ANO

\section{Figura 6}

Divisão por ano dos resultados encontrados

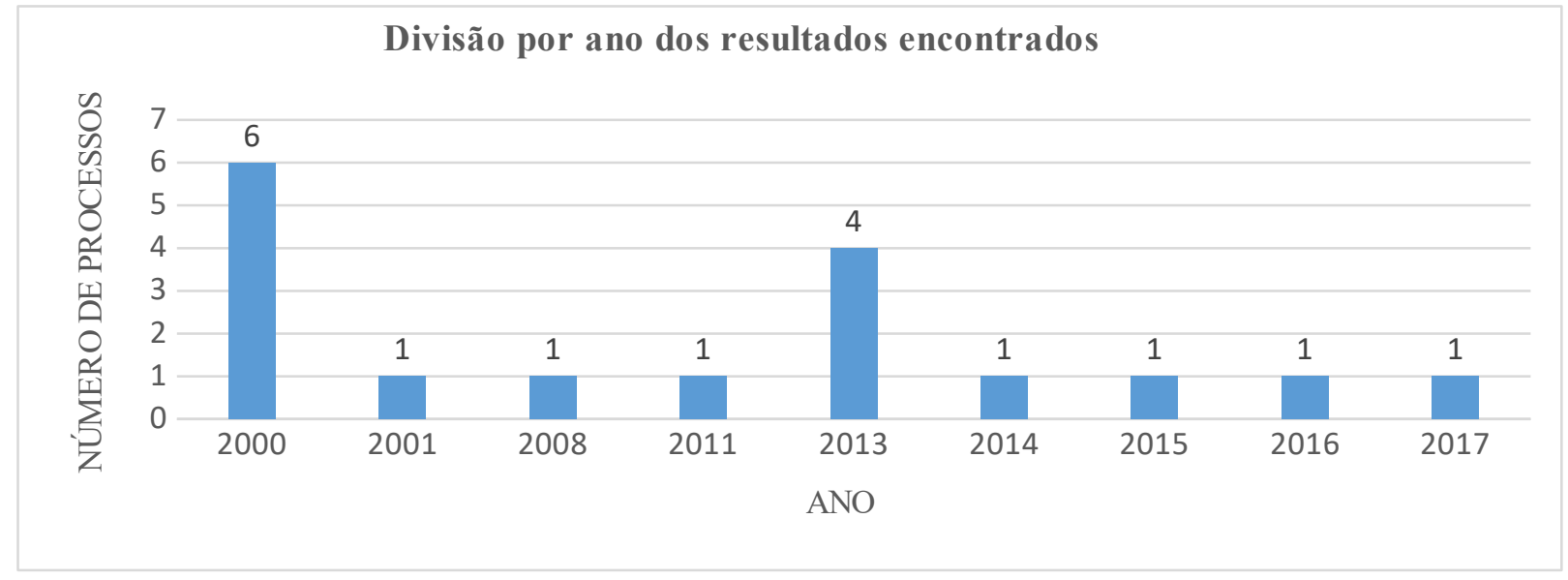

B) DIVISÃO POR ESTADO

\section{Figura 7}

Número de processos de Direito Civil divididos por estado 
- Distrito Federal 02

Minas Gerais 01

- Paraíba 01

Rio de Janeiro 02

- Rio Grande do Sul 03

- São Paulo 07
Número de processos de Direito Civil divididos por estado

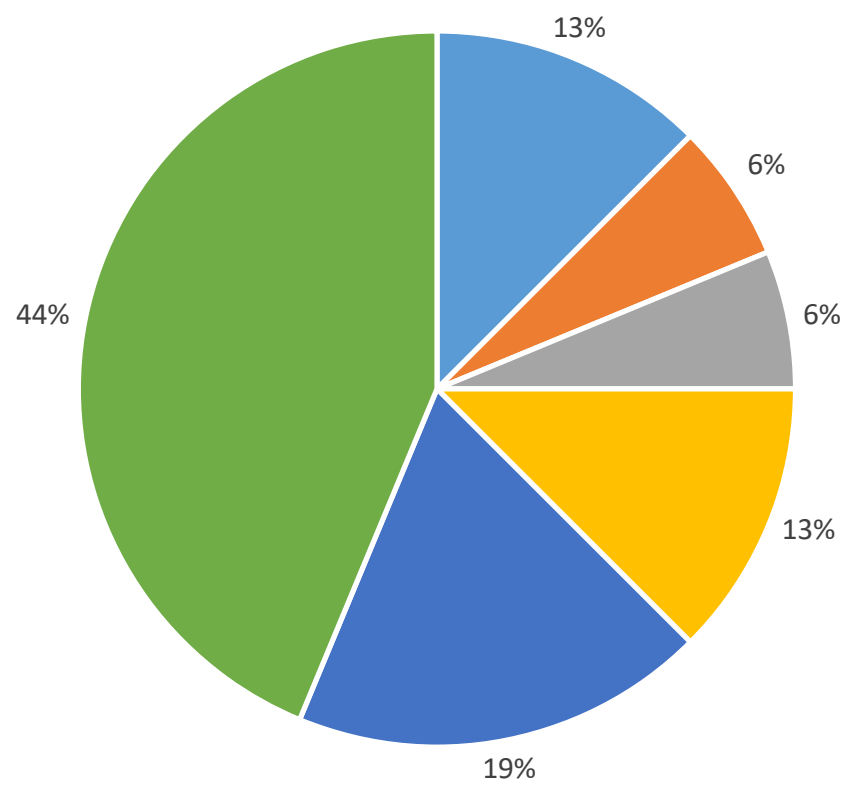

\section{ANÁLISE DOS ACÓRDÃOS}

Após se aplicar o método de refinamento, foram selecionados alguns acórdãos que serão trabalhados mais detidamente com vistas a se compreender se as decisões do Superior Tribunal de Justiça se utilizaram dos adjetivos de constitucionalização como fundamento e se a norma infraconstitucional era suficiente para a resolução da matéria, com o objetivo de se proceder a um teste de necessidade argumentativa.

\section{A) RESP 1183378 - RIO GRANDE DO SUL}

Esse recurso especial foi encontrado na pesquisa jurisprudencial no Superior Tribunal de Justiça no metadado utilizado neste trabalho: "constitucionalização". Trata-se de recurso especial contra acórdão do Tribunal de Justiça do Rio Grande do Sul, que denegou o pedido de habilitação de casamento entre duas mulheres, com fundamento na ausência de possibilidade jurídica do pedido, em virtude da previsão dos artigos 1.514, 1.517, 1535 e 1.565 do Código Civil de 2002, Lei $n^{\circ}$ 10,406, de 10 de janeiro de 2002, que tipificam a realização do casamento somente entre homem e mulher. 
Apoiou-se na alínea "a", inciso III, do artigo 105 da Constituição Federal de 1988, alegando ofensa ao artigo 1.521 do Código Civil de 2002, sob o fundamento de que o mencionado dispositivo não arrola a identidade de sexos entre as causas impeditivas do casamento.

O recurso foi julgado e provido em 25/10/2011, tendo como ministro relator o senhor Luis Felipe Salomão, de cuja ementa se destaca o trecho em que consta expressamente o termo "constitucionalização":

DIREITO DE FAMÍLIA. CASAMENTO CIVIL ENTRE PESSOAS DO MESMO SEXO (HOMOAFETIVO). INTERPRETAÇÃO DOS ARTS. 1.514, 1.521, 1.523, $1.535 \mathrm{e}$ 1.565 DO CÓDIGO CIVIL DE 2002. INEXISTÊNCIA DE VEDAÇÃO EXPRESSA A QUE SE HABILITEM PARA O CASAMENTO PESSOAS DO MESMO SEXO. VEDAÇÃO IMPLÍCITA CONSTITUCIONALMENTE INACEITÁVEL. ORIENTAÇÃO PRINCIPIOLÓGICA CONFERIDA PELO STF NO JULGAMENTO DA ADPF N. 132/RJ E DA ADI N. 4.277/DF. 1. Embora criado pela Constituição Federal como guardião do direito infraconstitucional, no estado atual em que se encontra a evolução do direito privado, vigorante a fase histórica da constitucionalização do direito civil, não é possível ao STJ analisar as celeumas que Ihe aportam "de costas" para a Constituição Federal, sob pena de ser entregue ao jurisdicionado um direito desatualizado e sem Iastro na Lei Maior. Vale dizer, o Superior Tribunal de Justiça, cumprindo sua missão de uniformizar o direito infraconstitucional, não pode conferir à lei uma interpretação que não seja constitucionalmente aceita.

Para que se possa proceder ao teste da necessidade argumentativa do discurso constitucionalizante mais adiante, hão de ser destacados os seguintes pressupostos: i) o legislador ordinário, no Código Civil de 2002, optou por não dar um conceito legal ao casamento; ii) ao dispor sobre união estável, o constituinte originário optou por estabelecer como pressuposto da união estável a diversidade de sexo; iii) no mesmo dispositivo constitucional que trata da união estável somente entre homem e mulher, situou-se a questão da sua conversão em casamento.

Em relação ao pressuposto (i), pode-se concluir que o discurso constitucionalizante é desnecessário para o deslinde da questão, porquanto o 
legislador ordinário poderia, facilmente, optar por alterar o Código Civil de 2002 para prever o casamento entre pessoas do mesmo sexo.

O ministro relator, contudo, em seu voto, valeu-se do discurso constitucionalizante inclusive para diminuir o papel do Poder Legislativo, sob o argumento de que caberia ao Poder Judiciário a proteção dos direitos humanos fundamentais das minorias, "por não ser compromissado com as maiorias votantes, mas apenas com a lei e com a Constituição". Mais adiante, o ministro afirma que

enquanto o Congresso Nacional, no caso brasileiro, não assume, explicitamente, sua coparticipação nesse processo constitucional de defesa e proteção dos socialmente vulneráveis, não pode o Poder Judiciário demitir-se desse mister, sob pena de aceitação tácita de um Estado que somente é "democrático" formalmente.

Quanto aos pressupostos (ii) e (iii), devem ser analisados em conjunto por estarem intrinsecamente relacionados. A Constituição Federal, no artigo 226, parágrafo $3^{\circ}$, estabeleceu que, "Para efeito da proteção do Estado, é reconhecida a união estável entre o homem e a mulher como entidade familiar, devendo a lei facilitar sua conversão em casamento". O constituinte originário optou por estabelecer como elemento da união estável a diversidade de sexos.

Na Arguição de Descumprimento de Preceito Fundamental (ADPF) 132/RJ, entretanto, a Suprema Corte estabeleceu que as uniões contínuas, públicas e duradouras entre pessoas do mesmo sexo devem ser consideradas como família. E o ministro Luis Felipe Salomão, ao relatar o recurso especial sobre a possibilidade de casamento civil entre pessoas do mesmo sexo, invocou, por diversas vezes, como fundamento do seu voto, a referida ADPF 132.

Tanto na ação constitucional quanto no recurso especial, o discurso constitucionalizante vai de encontro à própria Constituição, pois, se o constituinte originário optou por estabelecer a união estável como uma relação entre homem e mulher, como poderia o julgador invocar princípios da mesma Constituição para afastar uma previsão dela própria? O discurso constitucionalizante, nesse caso, estaria sendo usado contra a própria Carta Constitucional.

Não obstante, caso se entenda que a Constituição Federal não proibiu expressamente a união igualitária e se tome como base a premissa de que "o que 
não está proibido é permitido", ter-se-á hipótese de lacuna de responsabilidade do constituinte. Testando-se o discurso constitucionalizante nessa premissa, ainda assim, conclui-se pela inviabilidade de sua utilização, porquanto não cabe ao Poder Judiciário colmatar lacunas, mas sim ao Poder Legislativo, seja por via de emenda constitucional, seja mediante lei ordinária.

\section{B) HC 72547 - DISTRITO FEDERAL}

Esse acórdão figurou na pesquisa como resultante de dois dos metadados utilizados: "constitucionalização" e "eficácia dos direitos fundamentais". Traz o Habeas Corpus contra decisão do desembargador do Tribunal de Justiça do Distrito Federal e Territórios que manteve o decreto de prisão de devedora considerada depositária infiel nos autos de busca e apreensão, convertida em depósito, por sua recusa em entregar o automóvel objeto do contrato de alienação fiduciária. O impetrante do Habeas Corpus afirmou que o veículo não foi entregue à credora por motivo de força maior, eis que o automóvel fora furtado. Sustentou seu pedido na ilegalidade da prisão civil do devedor por infidelidade de fidúcia quando existe força maior que impossibilita a entrega do bem.

O acórdão, de relatoria do ministro Ruy Rosado de Aguiar, foi julgado em 01/06/2000. Da análise do seu acórdão e do voto, percebeu-se que o termo "constitucionalização" não foi utilizado em nenhum momento de maneira expressa, tendo sido encontrado na pesquisa por conter na informação da doutrina a obra Constitucionalização do Direito Civil, Boletim da Faculdade de Direito, Coimbra, 1998, V. LXXIV, (pp. 729- 750).

Em relação ao metadado "eficácia dos direitos fundamentais", o resultado foi encontrado no voto do ministro relator, no trecho que se destaca:

A dignidade é o valor que unifica o sistema, é "qualidade intrínseca da pessoa humana, irrenunciável e inalienável, na medida em que constitui elemento que qualifica o ser humano como tal" (Ingo Wolfgang Sarlet, A eficácia dos direitos fundamentais, p. 104), existe para todos e é igual em todos (Declaração Universal dos Direitos, ONU, 1948)".

Em seu voto, o ministro Ruy Rosado despende algumas linhas discorrendo 
acerca da eficácia horizontal da norma constitucional sobre as relações de Direito Privado. Cuida da eficácia direta e da indireta, invoca a doutrina alemã e se utiliza dos ensinamentos de autores como Ingo Sarlet, Robert Alexy e Luis Afonso Heck. Como o próprio relator destacou em sua fundamentação, "No caso dos autos, porém, a distinção entre eficácia direta e indireta frente a terceiros é irrelevante.".

Procedendo-se ao teste da necessidade argumentativa no acórdão em análise, verifica-se que, embora tenha sido encontrado na pesquisa com os metadados típicos desse conceito, não há correlação entre os argumentos da constitucionalização e da eficácia dos direitos fundamentais com a solução do caso, que se fundamentou nos próprios institutos do Direito Civil, em especial, na natureza jurídica do contrato de alienação fiduciária em garantia, conforme se destaca:

Assim, no âmbito do Direito Civil, no nível infraconstitucional, parece indispensável visualizar a alienação fiduciária em garantia de acordo com os princípios definidores da propriedade e do depósito, para concluir pela inexistência do contrato de depósito, ao menos com o fim de excluir a prisão civil como consequência do inadimplemento de um negócio bancário.

O ministro relator invocou, ainda, acórdão de lavra do ministro Adhemar Maciel, da $6^{\text {a }}$ Turma do Superior Tribunal de Justiça, que evidencia a utilização da própria norma infraconstitucional como elemento de convencimento, restando evidente a desnecessidade argumentativa do discurso constitucionalizante no caso sob análise. Veja-se: "o 'depositário infiel' só pode ser aquele do 'contrato de depósito' tradicional, (CC, art. 1.265) que se torna voluntariamente inadimplente".

\section{C) RESP 1365279 - SÃO PAULO}

O acórdão extraído do metadado "civil-constitucional" corresponde à ação de cobrança de multa de condomínio. Em síntese, o condomínio edilício ajuizou ação de cobrança em face do proprietário do bem que o alugou a terceiro e este incorreu em conduta antissocial, ao estabelecer uma banca de jogo de bicho no imóvel, com o consentimento daquele, além de outras infrações pretéritas. 
Deliberação da assembleia geral extraordinária aprovou a imputação ao proprietário de multa no valor de $\mathrm{R} \$$ 9.540,00 (nove mil, quinhentos e quarenta reais), sem, no entanto, notificá-lo para fins de apresentação de defesa, a qual foi objeto da ação de cobrança, mas tal pleito foi negado tanto em sede de primeiro grau como de segundo. Ao chegar ao Superior Tribunal de Justiça, sob relatoria do ministro Luis Felipe Salomão, esse entendeu que:

Por se tratar de punição imputada por conduta contrária ao direito, na esteira da visão civil-constitucional do sistema, deve-se reconhecer a aplicação imediata dos princípios que protegem a pessoa humana nas relações entre particulares, a reconhecida eficácia horizontal dos direitos fundamentais que, também, deve incidir nas relações condominiais, para assegurar, na medida do possível, a ampla defesa e o contraditório. Com efeito, buscando concretizar a dignidade da pessoa humana nas relações privadas, a Constituição Federal, como vértice axiológico de todo o ordenamento, irradiou a incidência dos direitos fundamentais também nas relações particulares, emprestando máximo efeito aos valores constitucionais.

Para a resolução do caso, foi exposta a fundamentação com base na aplicação dos princípios constitucionais, numa dimensão civil-constitucional, bem como na aplicação da eficácia horizontal dos direitos fundamentais, em que hão de ser aplicados o contraditório e a ampla defesa ao artigo 1.337, parágrafo único, do Código Civil de 2002.

Com efeito, o Superior Tribunal de Justiça utilizou-se da aplicação do contraditório e da ampla defesa conferida na Constituição Federal, num discurso constitucionalizante, o qual poderia ser solucionado com a norma infraconstitucional, na aplicação analógica ao artigo 57 do Código Civil de 2002.

D) RESP 1335153 E RESP 1334097 - RIO DE JANEIRO

O REsp 1335153, que se reporta a direito ao esquecimento, retirado do metadado "civil-constitucional", retrata e soluciona o caso de reparação de danos morais, materiais e à imagem em face da TV Globo. Trata-se da simulação do crime de homicídio no ano de 1958, em que se "sustentam que o crime fora 
esquecido pelo passar do tempo, mas que a emissora ré cuidou de reabrir as antigas feridas dos autores, veiculando novamente a vida, a morte e a pós-morte de Aida Curi, inclusive explorando sua imagem, mediante a transmissão do programa chamado Linha Direta-Justiça".

Após análise detida sobre aspectos da liberdade de expressão, responsabilidade civil, direito ao esquecimento e direito à imagem, a Corte Superior negou provimento ao recurso, apesar dos votos vencidos, considerando tanto a análise da norma infraconstitucional bem como dos aspectos limitativos da responsabilidade civil. Destaca o relator, Luis Felipe Salomão: "No caso em apreço, o confronto entre liberdade de informação e os direitos da personalidade, a par de transitar também pelos domínios do direito constitucional, pode ser bem solucionado a partir da exegese dos arts. 11, 12, 17, 20 e 21, do Código Civil.".

Apesar da menção à constitucionalização do Direito Civil, esse não foi essencial para a resolução da matéria, para a qual se aplicou, corretamente, a norma infraconstitucional, já que se mostrou suficiente à solução do caso.

Já o REsp 1334097, que também trata do direito ao esquecimento, expõe o pedido de reparação de danos morais em face da TV Globo, em que o requerente teve sua imagem e nome vinculado ao programa Linha-Direta Justiça, referente ao caso da Chacina da Candelária, no qual fora "indiciado como coautor/partícipe da sequência de homicídios ocorridos em 23 de julho de 1993, na cidade do Rio de Janeiro", vindo a ser, no entanto, após julgamento, "absolvido por negativa de autoria pela unanimidade dos membros do Conselho de Sentença".

Segundo o requerente, "levou-se a público situação que já havia superado, reacendendo na comunidade onde reside a imagem de chacinador e o ódio social, ferindo, assim, seu direito à paz, anonimato e privacidade pessoal, com prejuízos diretos também a seus familiares".

O Superior Tribunal de Justiça, ao julgar o referido caso, fez utilização dos mesmos fundamentos do Recurso Especial anterior, de $n^{\circ} 1335153$, ressaltando inclusive que o caso pode ser solucionado com amparo na exegese dos artigos 11, 12, 17, 20 e 21 do Código Civil de 2002, porém argumentou, ao final, a ofensa à dignidade da pessoa humana, ao permitir nova veiculação do fato, obtendo resultado distinto daquele, como ressalta em seu acórdão o ministro Luiz Felipe Salomão: "na legislação infraconstitucional, adota-se com suficiente clareza essa pauta, em regra, preferencial pela dignidade da pessoa humana quando em 
conflito com outros valores, como, por exemplo, os arts. 11, 20 e 21 do Código Civil de 2002".

Apesar dos fundamentos comuns aos REsp. 1335153 e REsp 1334097, o resultado foi distinto, o que demonstra uma das facetas da aplicação dos direitos fundamentais, pondo em xeque uma das características basilares da norma jurídica, configurada na previsibilidade.

\section{E) RESP 1179259 - MINAS GERAIS}

Dos acórdãos extraídos do metadado "eficácia dos direitos fundamentais", analisa-se o REsp 1179259, julgado em 14/05/2103, sob a relatoria da ministra Nancy Andrighi, referente à matéria de Usufruto, cujo dissídio tem como objeto a extinção do usufruto por não uso ou não fruição. A discussão reside no artigo 1.410, VIII, do Código Civil de 2002, o qual estabeleceu a extinção do usufruto pelo não uso ou fruição do bem pelo titular, porém não disciplinou o prazo de omissão do usufrutuário.

Para solucionar a ausência de prazo, o arresto se utilizou da Teoria de Direito Civil- Constitucional e das cláusulas gerais, reconhecendo que,

Assim, se, de um lado, o Código Civil preferiu não atribuir prazo determinado para configuração da hipótese em exame e, de outro lado, as relações de direito real são pautadas pelo cumprimento da função social da propriedade (seu vetor axiológico), infere-se que a extinção do usufruto pelo não uso pode ser levada a efeito, independentemente de prazo certo, sempre que, diante das circunstâncias, se verificar o não atendimento de seus fins sociais.

Já a decisão da apelação no Tribunal de Justiça de Minas Gerais adotou argumento diverso, pautado pela hermenêutica tradicional. Considerou a aplicação da analogia do artigo 205 do Código Civil de 2002, que disciplina o prazo geral de dez anos, quando não Ihe haja fixado outro prazo.

Destaca-se que a solução utilizada pelo Supremo Tribunal de Justiça pode causar certa insegurança jurídica, ao não estipular lapso razoável para que o direito real de usufruto seja aniquilado. 
Assim, percebe-se que o Tribunal Superior adotou um discurso constitucionalizante, ao vincular o direito real de usufruto à função social da propriedade, contida no artigo $5^{\circ}$, inciso XXIII, da Constituição Federal de 1988, o que poderia ser resolvido com análise da própria norma infraconstitucional, no caso, o Código Civil, por analogia ao seu artigo 205.

\section{F) AGINT NO ARESP 330494 - SÃO PAULO}

Acórdão retirado do metadado eficácia dos direitos fundamentais, sem o uso das aspas, cuja matéria envolve violação aos artigos 54, II, e 55 do Código Civil de 2002 e defende que não houve ofensa ao princípio da plena liberdade associativa, ao não aceitar a empresa para integrar os quadros da associação.

A ministra relatora Maria Isabel Galotti não acatou os fundamentos da associação, alegando violação aos "princípios constitucionais, que impedem discriminações arbitrárias em associações profissionais". Afirmou ainda que os artigos 54, II, e 55 do Código Civil de 2002 devem respeitar a Constituição Federal numa dimensão de eficácia horizontal dos direitos fundamentais. Veja-se:

As associações devem observar a teoria da eficácia horizontal dos direitos fundamentais, uma vez que o relacionamento vertical entre as normas normas constitucionais e normas infraconstitucionais, por exemplo - deve ser apresentado, de tal forma, que o conteúdo de sentido da norma inferior deve ser aquele que mais intensamente corresponder ao conteúdo de sentido da norma superior.

Com efeito, é patente a utilização do discurso constitucionalizante ao se aplicar diretamente a Constituição Federal numa norma infraconstitucional (artigos 54, II, e 55 do Código Civil), a qual já determina a autonomia privada das associações e empresas em seus estatutos para exclusão, admissão e demissão dos associados.

G) RESP 1626739 - RIO GRANDE DO SUL

Esse Recurso Especial foi encontrado na pesquisa empírica com a utilização do metadado eficácia dos direitos fundamentais, sem o uso das aspas. É um 
recurso contra acórdão do Tribunal de Justiça do Rio Grande do Sul que denegou, em sede de apelação, a retificação de sexo no registro civil de nascimento sem que a pessoa seja submetida a cirurgia de transgenitalização. Foi julgado e provido em 09/05/2017, sob relatoria do ministro Luis Felipe Salomão, de cujo voto se extrai:

No exercício da missão constitucional de guardião e intérprete último da legislação federal infraconstitucional, o STJ funciona como verdadeiro "Tribunal da Cidadania", cabendo-Ihe considerar as modificações dos usos e costumes da sociedade quando do julgamento de questões relevantes, observada a forca normativa dos princípios constitucionais fundamentais que funcionam como vetores interpretativos e meios integrativos de todo o sistema jurídico nacional. Nesta hipótese, há o que a doutrina denomina de posição contramajoritária do Poder Judiciário. "Em busca do cumprimento de tal mister, o exame da presente controvérsia reclama a superação de preconceitos e estereótipos, bem como o exercício da alteridade, isto é, a capacidade de se colocar no lugar do outro".

Entendeu o Ministro, cujo voto foi vencedor, que é devida a alteração do sexo no registro público de nascimento, pois:

A mera alteração do prenome das pessoas transexuais, contudo, segundo parece, não alcança o escopo protetivo encartado na norma jurídica infralegal, além de descurar da imperiosa exigência de concretização do princípio constitucional da dignidade da pessoa humana, que traduz a máxima antiutilitarista segundo a qual cada ser humano deve ser compreendido como um fim em si mesmo e não como um meio para a realização de finalidades alheias ou de metas coletivas.

A Lei de Registros Públicos, Lei n 6.015, de 31 de dezembro de 1973, no artigo 54, item 2, dispõe que o sexo do registrando é elemento do assento de nascimento, o qual se extrai do atestado do médico, verificado na ocasião do nascimento, informação esta que é aposta na declaração de nascido vivo. Ademais, é da própria razão de ser dos registros públicos que espelhem a 
realidade dos fatos, o que inclusive foi mencionado no voto vencedor, mas para relativizar:

Assim, a segurança jurídica pretendida com a individualização da pessoa perante a família e a sociedade - ratio essendi do registro público, norteado pelos princípios da publicidade e da veracidade registral - deve ser compatibilizada com o princípio fundamental da dignidade da pessoa humana, que constitui vetor interpretativo de toda a ordem jurídicoconstitucional.

Não se pode perder de vista a ideia de que possibilitar a alteração de sexo sem que haja a cirurgia de transgenitalização é permitir que uma realidade apenas psicológica se sobreponha à realidade biológica e, portanto, fática, o que fere frontalmente a essência dos registros públicos e enseja situação de grande insegurança para toda a sociedade, em detrimento do suposto direito à felicidade, em especial se considerada a vedação à "inclusão, ainda que sigilosa, da expressão transexual ou do sexo biológico".

Procedendo-se à análise argumentativa do discurso constitucionalizante nesse caso, vê-se, claramente, que ao se retirar o excesso de princípios e supostos direitos invocados (direito de liberdade e desenvolvimento e expressão da própria personalidade; direito ao reconhecimento perante a lei; direito fundamental à felicidade; dignidade da pessoa humana, entre outros), o resultado seria diverso, para prevalecer a essência dos registros públicos, que é espelhar a realidade.

Há grande insegurança decorrente da retificação de sexo no registro civil de nascimento sem a cirurgia de transgenitalização, em especial se considerado o caráter sigiloso dessa averbação, que retira dos demais a possibilidade de conhecer a realidade biológica e fática de determinada pessoa.

\section{CONTROLE DE RESULTADO}

Conforme o exposto, o discurso constitucionalizante é empregado pela doutrina compreendendo diversos adjetivos, como a constitucionalização do Direito Civil, Civil-Constitucional, despatrimonialização e eficácia dos direitos fundamentais, mas permeado de assimetria conceitual e influenciando as decisões judiciais, como as proferidas pelo Superior Tribunal de Justiça, objeto de 
estudo do presente trabalho. Com base na análise empírica sobre alguns metadados expressos, conclui-se que:

a) os resultados obtidos com os metadados demonstram que o substantivo constitucionalização não é encontrado com tanta expressividade nos acórdãos do Superior Tribunal de Justiça, diferentemente das acepções civil-constitucional e eficácia dos direitos fundamentais, de maior uso em seus argumentos;

b) além disso, ficou demonstrado que a utilização desses dados acontece desde os anos 2000, indicando um debate mais atual no âmbito da jurisprudência, para assunto primitivo na doutrina estrangeira;

c) a opção empregada na escolha dos arestos é resultado das técnicas de refinamento, as quais se caracterizam como filtros para extrair apenas aquelas decisões que consideraram a análise das relações individuais com a base axiológica constitucional, seguindo as noções dos metadados conceituados;

d) dessa análise, pode ser verificado um discurso constitucionalista do Direito Civil, em que, não raras vezes, a solução da lide é dada com análise e preponderância da Constituição Federal, relegando a norma infraconstitucional, no caso o Código Civil, ou até mesmo sem padrão metodológico, desconsiderando os conceitos tradicionais do Código Civil e da hermenêutica clássica.

\section{REFERÊNCIAS}

AgInt no AREsp 330494/SP, rela. ministra Maria Isabel Gallotti, Quarta Turma, julgado em 29/09/2016, publicado no DJe de 05/10/2016. Disponível em: http://www.stj.jus.br/scon/jurisprudencia/doc.jsp? $\underline{\text { livre }=330494 \& b=A C O R \& p=\text { true } \& \mathrm{t}=J \cup R|D| C O \& \mid=10 \& i=2}$

Barroso, L. R. (2005, abril). Neoconstitucionalismo e constitucionalização do Direito (O triunfo tardio do direito constitucional no Brasil). Revista de Direito Administrativo, 240, 1-42. ISSN 2238-5177. Disponível em: http://dx.doi.org/10.12660/rda.v240.2005.43618 
Constituição da República Federativa do Brasil de 1988. (1988, 5 de outubro).

Brasília: Casa Civil da Presidência da República. Disponível em:

http://www.planalto.gov.br/ccivil_03/constituicao/ constituicao.htm

Fachin, L. E. (2008). Questões do Direito Civil brasileiro contemporâneo. Rio de Janeiro: Renovar.

HC 12.547/DF, rel. ministro Ruy Rosado de Aguiar, Quarta turma, julgado em 01/06/2000, publicado no DJ de 12/02/2001, p. 115. Disponível em: http://www.stj.jus.br/scon/jurisprudencia/ doc.jsp? livre $=12547 \& b=$ ACOR $\& p=$ true $\& \mid=10 \& i=1$

Lei $n^{\circ}$ 6.015, de 31 de dezembro de 1973. (1973, 31 de dezembro). Dispõe sobre os registros públicos, e dá outras providências. Brasília: Casa Civil da Presidência da República. Disponível em: http://www.planalto.gov.br/ccivil_03/leis/16015compilada.htm

Lei $n^{\circ}$ 10.406, de 10 de janeiro de 2002. (2002, 10 de janeiro). Institui o Código Civil. Brasília: Casa Civil da Presidência da República. Disponível em: http://www.planalto.gov.br/ccivil_03/leis/2002/110406.htm

Lôbo, P. L. N. (1999, janeiro/março). Constitucionalização do Direito Civil. Revista de Informação Legislativa, 36(141), 99-109.

Moraes, M. C. B. de (2006, julho/dezembro). A constitucionalização do Direito Civil e seus efeitos sobre a responsabilidade civil. Direito, Estado e Sociedade, 9(29), 233-258.

Moraes, M. C. B. de (2010). Na medida da pessoa humana: Estudos de direito CivilConstitucional. Rio de Janeiro: Renovar.

Reis, T. (2017, abril/junho). Dogmática e Incerteza Normativa: Crítica ao Substancialismo Jurídico do Direito Civil-Constitucional. Revista de Direito Civil Contemporâneo, 71(4), 214-238. 
REsp 1183378/RS, rel. ministro Luis Felipe Salomão, Quarta turma, julgado em 25/10/2011, publicado no DJe de 01/02/2012. Disponível em:

http://www.stj.jus.br/scon/jurisprudencia/doc. jsp? $\underline{\text { livre }=1179259 \& b=A C O R \& p=\text { true } \& \mid=10 \& i=1}$

REsp 1179259/MG, rela. ministra Nancy Andrighi, Terceira Turma, julgado em 14/05/2013, publicado no DJe de 24/05/2013. Disponível em: http://www.stj.jus.br/scon/jurisprudencia/doc. jsp? livre $=1179259 \& b=$ ACOR $\& p=$ true $\& 1=10 \& i=1$

REsp 1334097/RJ, rel. ministro Luis Felipe Salomão, Quarta Turma, julgado em 28/05/2013, publicado no DJe de 10/09/2013. Disponível em: http://www.stj.jus.br/scon/jurisprudencia/doc. jsp? $\underline{\text { livre }=1334097 \& b=\text { ACOR } \& p=\text { true } \& t=J U R I D I C O \& \mid=10 \& i=12}$

REsp 1335153/RJ, rel. ministro Luis Felipe Salomão, Quarta Turma, julgado em 28/05/2013, publicado no DJe de 10/09/2013. Disponível em: http://www.stj.jus.br/scon/jurisprudencia/doc. jsp? $\underline{\text { livre }=1335153 \& b=\text { ACOR \& } p=\text { true } \& t=J U R I D|C O \&|=10 \& i=7}$

REsp 1365279/SP, rel. ministro Luis Felipe Salomão, Quarta Turma, julgado em 25/08/2015, publicado no DJe de 29/09/2015. Disponível em: http://www.stj.jus.br/scon/jurisprudencia/doc. jsp? $\underline{\text { livre }=1365279 \& b=A C O R \& p=\text { true } \& \mid=10 \& i=1}$

REsp 1626739/RS, rel. ministro Luis Felipe Salomão, Quarta Turma, julgado em 09/05/2017, publicado no DJe de 01/08/2017. Disponível em: http://www.stj.jus.br/scon/jurisprudencia/tc. jsp? livre=1626739\&\&tipo_visualizacao=RESUMO\&b=ACOR\&thesaurus=JURIDICO $\underline{\mathrm{p}=\text { true }}$

Rodrigues, O. L., Jr. (2014, outubro/dezembro). Entrevista com Nelson Nery Jr. Revista de Direito Civil Contemporâneo, 1, 367-388.

Schreiber, A. (2013). Direito Civil e Constituição. São Paulo: Atlas. 
Silva, V. A. da (2014). A constitucionalização do direito: Os direitos fundamentais nas relações entre particulares (1a ed. 4a tir.). São Paulo: Malheiros.

Streck, L. L. (2012, abril/junho). Do pamprincipiologismo à concepção

hipossuficiente de princípio: Dilemas da crise do Direito. Revista de Informação Legislativa, 19(194), 7-21.

Superior Tribunal de Justiça. (2004). A era digital. Disponível em:

http://www.stj.jus.br/sites/STJ/default/pt_BR/Institucional/História/A-eradigital

Tepedino, G. (2008, abril/junho). Entrevista com Antonio Junqueira de Azevedo. Revista Trimestral de Direito Civil, 34, 299-308.

\section{Nota sobre pessoas autoras:}

Andrea Sales Santiago Schmidt: Mestre em Relações Privadas no Centro Universitário Sete de Setembro (UNI7) do Estado do Ceará. Especialista em Registros Públicos e Sucessões pela Universidade Estadual do Ceará. Tabeliã e Registradora. E-mail: andreasantiago85@yahoo.com.br

Janile Lima Viana: Mestre em Relações Privadas pelo Centro Universitário Sete de Setembro (UNI7) - Linha de pesquisa: Relações privadas, direitos humanos e desenvolvimento. Especialista em Direito Processual pelo Centro Universitário Sete de Setembro (2008). Advogada atuante no Estado do Ceará. Doutoranda em Direito na Universidade Católica de Pernambuco (UNICAP).

Leonardo José Peixoto Leal: Doutor em Direito pela Universidade Federal do Ceará - UFC (2017). Mestre em Direito Constitucional pela Universidade de Fortaleza - UNIFOR (2010). Professor da Graduação e Pós-Graduação em Direito da Universidade de Fortaleza . Diretor Acadêmico da Escola Superior de Advocacia da Ordem dos Advogados do Brasil, Seccional do Cerá - ESA/CE (2019-2021). 
Presidente da Comissão de Estudo e Defesa da Concorrência da Ordem dos Advogados do Brasil, Seccional do Ceará - OAB/CE (2016-2018); (2019-2021). Membro efetivo da Comissão de Defesa do Consumidor da OAB/CE.

Data de submissão: 20/12/2019

Data de aprovação: 19/06/2020 